\title{
Identification of the new pathogen (Stemphylium lycopersici) causing leaf spot on pepino (Solanum muricatum)
}

\begin{abstract}
Pepino (Solanum muricatum var. pepino) plants were found affected by an extensive leaf spot caused by plant pathogenic fungi during a survey in the Cameron highlands, Pahang state, Malaysia. Symptomatic leaf samples were collected from infected pepino plants and cultivated on PDA medium, and the pathogen was isolated and purified; then, consequently, all isolates were identified as Stemphylium lycopersici on the basis of their cultural and morphological characteristics and combined sequences of the internal transcribed spacer (ITS) and glyceraldehyde-3-phosphate dehydrogenase (gpd) regions. A pathogenicity assay on detached leaves further confirmed that S. lycopersici causes leaf spot disease. To the best of our knowledge, this is the first report of S. lycopersici causing leaf spot on pepino in Malaysia and worldwide.
\end{abstract}

Keyword: Leaf spot; Pepino; Phylogeny; Solanum muricatum var. pepino; Stemphylium lycopersici 